\title{
The German Version of the State Adult Attachment Measure (SAAM)
}

\author{
Structure, Reliability, and Validity
}

\author{
Lynne Marie Stöven® and Philipp Yorck Herzberg®
}

\author{
Department of Personality Psychology and Psychological Assessment, Helmut-Schmidt University/University of the German Federal \\ Armed Forces Hamburg, Germany
}

\begin{abstract}
This study examined the structure, reliability, and validity of a German version of the State Adult Attachment Measure (SAAM) by Gillath and colleagues (Gillath et al., 2009). A satisfactory fit was found for the hypothesized three-factor model (comparative fit index = .840; RMSEA $=.071$ with $95 \% \mathrm{Cl}=.063, .079)$. The German SAAM subscales showed high internal consistency. Convergent and discriminant validity supported the state interpretation of the subscale scores. Furthermore, German SAAM scores explained variance in outcomes of mental health and well-being over and beyond trait attachment with the Security subscale accounting for most of the variance. One-week test-retest reliability did not differ from a trait attachment measure (Experiences in Close Relationship Scale). The DE-SAAM could capture fluctuations in Security scores induced by a security prime $(p=.007, d=0.49)$. No effect of the prime condition (security vs. neutral) was found on Anxiety and Avoidance. Further research is needed to examine the validity of the state interpretation of all DE-SAAM subscale scores.
\end{abstract}

Keywords: state attachment style, state attachment measure, adult attachment, validation

Attachment theory was first developed by Bowlby (1982) as a conceptual framework for differences in relationship expectations and behaviors. Experiences with early caregivers result in internal working models of self and others which serve as a prototype for future relationships (Bowlby, 1982). The model of self includes beliefs about one's self-worth and expectations about others' reactions to oneself, while the model of others consists of beliefs about the availability, trustworthiness, and supportiveness of others (Griffin \& Bartholomew, 1994).

Hazan and Shaver (1987) developed a typology of adult attachment styles in romantic relationships. They discriminated between a secure, an avoidant, and a preoccupied type according to infant attachment patterns identified by Ainsworth (1978). Bartholomew (1990) additionally discriminated between a dismissive type and a fearful type. These four attachment types were based on the two dimensions of the internal working models as well as their valence (positive vs. negative; Bartholomew \& Horowitz, 1991). The model of self is reflected by the anxiety dimension of attachment style (Brennan et al., 1998; Griffin \& Bartholomew, 1994). Anxiety is associated with the fear of rejection and abandonment by a romantic partner as anxious individuals do not feel love worthy due to a negative model of self. A negative working model of others relates to attachment avoidance, which is characterized by discomfort with closeness and reluctance in trusting others (Bowlby, 1969, 1982). Attachment style can be assessed either as a dimensional or typological variable, depending on the theoretical framework of the instrument.

\section{Correlates of Attachment Style}

Adult attachment style has shown to be a reliable predictor for numerous relationship outcomes such as relationship satisfaction, happiness, duration, and the number of breakups (Feeney \& Noller, 1992; Kirkpatrick \& Hazan, 1994; Noftle \& Shaver, 2006; Shaver \& Brennan, 1992). As mentioned before, internal working models of self and others play an important role in coping with threats and distress (Bowlby, 1969, 1982; Griffin \& Bartholomew, 1994; Karreman \& Vingerhoets, 2012). Poorer emotion regulation abilities and less resilience associated with insecure attachment lead to lower well-being compared to secure individuals (Karreman \& Vingerhoets, 2012). Furthermore, insecure attachment shows associations with mental health outcomes such as depressive symptoms (Bifulco et al., 2002; Roberts et al., 1996). 


\section{Stability of Attachment Style}

Attachment style is a relatively stable disposition throughout the lifespan. Recent research has shown that attachment style might be less stable than expected (Fraley \& Roisman, 2019). Although there seems to be a continuous factor, attachment styles are less stable throughout childhood and adolescence than throughout adulthood (Fraley \& Roisman, 2019; Jones et al., 2018). Experiences in relationships can affect attachment. For example, positive relationship experiences can increase attachment security through changes in the internal working models toward more positive models of self and others (Cozzarelli et al., 2003). On the other hand, relationship breakups can lead to a temporary shift toward insecure attachment (Hammond \& Fletcher, 1991; Kirkpatrick \& Hazan, 1994).

Not only real-life relationship experiences can result in (temporary) changes in attachment style but also priming a certain attachment style (e.g., by imagining a positive experience) can lead to variability (Carnelley \& Rowe, 2007, 2010; Rowe \& Carnelley, 2003). These findings support the theory of numerous co-existing working models, which can be activated as a response to changing contexts, rather than one universal invariable working model (Baldwin \& Fehr, 1995; Baldwin et al., 1996).

\section{Assessing Attachment Style}

Subjective self-reports have shown to be a reliable and valid way to assess individual attachment patterns (Sibley et al., 2005). Depending on the theoretical scope, attachment measures focus on assessing either attachment dimensions or distinct attachment types. The Relationship Questionnaire (Bartholomew \& Horowitz, 1991) and the Attachment Style Questionnaire (Feeney et al., 1994) are frequently used instruments assessing attachment on a typological level. The Experiences in Close Relationship (ECR) scale developed by Brennan et al. (1998) is one of the most commonly used instruments to assess trait attachment style on a dimensional level. It captures individual attachment profiles on two orthogonal dimensions (Anxiety and Avoidance). Security is defined as a low score on both dimensions. The ECR and its revised version the ECR-R (Fraley et al., 2000) have been established as standard measures and were widely used by international researchers over the past decades. Today, the ECR is available in numerous languages.

Standard attachment measures are not eligible to capture fluctuations in attachment style. Due to their original conception, temporary variation in security and insecurity can hardly be detected (Gillath et al., 2009). The instruction of the ECR explicitly asks about participants' general ECRs (Brennan et al., 1998). Levels of attachment security affect various emotional, cognitive, and behavioral outcomes (Gillath \& Karantzas, 2019), which are of great interest for different research fields.

Gillath et al. (2009) developed the State Adult Attachment Measure (SAAM) to identify temporary changes in attachment dimensions. In addition to the dimensions Anxiety and Avoidance, the SAAM includes Security as an independent dimension accordant with Hazan and Shaver's (1987) concept of adult attachment style. The three-factor structure provided the best fit to the data (comparative fit index $[\mathrm{CFI}]=.90$, RMSEA $=.07$ ) compared to a one-, two-, and four-factor model (Study 2, Gillath et al., 2009). The SAAM allows measuring a snapshot of the currently activated working model by instructing participants to indicate how they feel "right now." Furthermore, the statements also refer to the present moment (e.g., "I really need to feel loved right now."). The current attachment style is captured in a multidimensional profile on three subscales (Anxiety, Avoidance, and Security). Test-retest stability scores after three months were reasonable $(.51, .53$, and .59 for SAAM Anxiety, Avoidance, and Security, respectively) and lower than that of trait measures (Study 3). Regarding convergent and discriminant validity, the SAAM showed high correlations with measures for similar constructs (i.e., Relationship Questionnaire and ECR) and lower correlations with conceptually different constructs (e.g., Positive and Negative Affect schedule; Bosmans et al., 2014; Gillath et al., 2009). Finally, the SAAM could predict relationship quality over and beyond the Adult Temperament Questionnaire (Rothbart et al., 2000; $\Delta R^{2}=.24, p<.01$ ), a personality measure based on the five-factor model of personality indicating good incremental validity.

\section{Study 1}

While the ECR is available in many languages, to the best of our knowledge, translations for the SAAM only exist in Korean, Italian, and Chinese (Ma et al., 2012; Park \& Lee, 2012; Trentini et al., 2015). Due to the implications of temporary fluctuations in attachment style for emotional, cognitive, and behavioral outcomes, a measure that is capable of reliably assessing state attachment is essential for future research in this field. In this study, we aim to test the structure of a German version of the SAAM (DE- 
SAAM) as well as its convergent, discriminant, and incremental validity.

First, we tested the fit of the three-factor model to data of a German sample. Convergent and discriminant validity was computed in a single SEM model with correlated latent variables. For convergent validity, the subscales of the DE-SAAM with those of the ECR were correlated. Discriminant validity was determined by correlating the DE-SAAM with the state version of the Positive and Negative Affect Schedule (PANAS, Watson et al., 1988). For investigating incremental validity, associations with measures of mental health and wellbeing were tested by means of hierarchical regression analyses.

\section{Method}

\section{Participants and Procedure}

Participants for the online survey were recruited by e-mail and social media platforms. Students of the Helmut Schmidt University in Hamburg could gain achievement points for participating. A total of 264 completed the survey. Thirty-three cases had to be excluded due to missing data, resulting in a final sample size of 231. Given this sample size, the study has a power of .93 to detect effect sizes of $\rho=.20$.

Among those were $53.7 \%$ female, $45.5 \%$ male, and $0.9 \%$ nongender specific. The age ranged from 19 to 65 years $(M=26.96 ; S D=9.27) .36 .4 \%$ were single, $48.9 \%$ in a relationship, and $14.7 \%$ married. The research data are archived and can be accessed under the Open Science Framework link https://osf.io/xsqju/ (Stöven \& Herzberg, 2020).

\section{Measures}

\section{State Adult Attachment}

The translation process consisted of two steps. First, one author and a bilingual with expertise in the research field independently translated the 21 items of the SAAM into German (e.g., "I really need to feel loved right now" and "I feel like others care about me"). The results were compared and discussed, and items were adjusted resulting in a consented version. In a second step, this version of the DE-SAAM was translated back into English by a bilingual professional and an English native speaker fluent in German without expertise in this research field. Both versions showed high congruence with the original wording of the SAAM, as well as with its semantic content. In a third step, a small sample $(N=6)$ completed the preliminary version of the DE-SAAM and gave feedback on comprehension issues. Only a few adjustments were necessary to improve comprehensiveness in accordance with the intended structure. The instruction and 7-point rating scale $(1=$ "disagree strongly" to $7=$ "agree strongly") of the SAAM were applied. The complete questionnaire is provided in Electronic Supplementary Material 1.

\section{Trait Adult Attachment}

For better comparability, measures for testing validity were chosen analogous to those used in previous studies (Gillath et al., 2009; Trentini et al., 2015).

To assess adult attachment, we used the German translation of the ECR (Brennan et al., 1998) by Neumann et al. (2012). The questionnaire consists of 36 items with 18 items assessing attachment anxiety (e.g., "I'm afraid that I will lose my partner's love") and 18 items assessing attachment avoidance (e.g., "I prefer not to be too close to romantic partners") on a 7-point rating scale ranging from 1 (strongly disagree) to 7 (strongly agree).

\section{State Measure of Positive and Negative Affect}

The German version of the PANAS (Watson et al., 1988) by Breyer and Bluemke (2016) provides a measure to assess the emotional state with 20 adjectives describing different feelings and emotions. Two scales of ten items capture the dimensions of negative (e.g." "hostile" and "irritable") and positive (e.g., "enthusiastic" and "proud") affect on a 5point rating scale ranging from 1 ("not at all") to 5 ("extremely"). To assess the current emotional state, participants were instructed to indicate how they feel "right now."

\section{State Anxiety}

The Anxiety in Non-Clinical Contexts Scale (Mohr \& Müller, 2014a) allows the assessment of anxiety symptoms for nonclinical samples. Participants rate seven statements on typical anxiety symptoms (e.g., "I feel very uncomfortable in confined spaces." "I blush easily.") on a 7point rating scale from 1 ("does not apply at all") to 7 ("almost absolutely true").

\section{State Depression}

Mohr and Müller (2014b) further developed the Depressiveness in Non-Clinical Contexts scale to provide a measure for depressiveness in nonclinical samples. Participants rate the frequency of eight statements referring to typical depressive symptoms (e.g., "A lot of things seem so pointless.") on a 7-point rating scale from 1 ("never") to 7 ("almost always").

\section{Satisfaction with Life}

The German version of the Satisfaction with Life Scale (SWLS; Diener et al., 1985) by Janke and Glöckner-Rist (2012) allows measuring the extent to which individuals 
are satisfied with their current life "all in all." Five statements (e.g., "I am satisfied with my life." "My living standards are excellent.") are rated on a 7-point rating scale from 1 ("does not apply at all") to 7 ("entirely true").

\section{Design}

This study employed a cross-sectional design using an online survey. To test the hypothesized three-factor model of the DE-SAAM, a confirmatory factor analysis was applied. Each of the three latent variables (Anxiety, Avoidance, and Security) was measured by seven items. Error terms in the model were uncorrelated. Correlations between factors were freely estimated. The assumption of multivariate normality was violated (Mardia's normalized estimate of multivariate kurtosis $=28.00$ ). Thus, the R-package lavaan was used with the robust MLMVS estimator (maximum likelihood estimation with robust SEs and a mean- and variance-adjusted test statistics that are robust to non-normality). Latent associations were tested with the SEM approach.

\section{Results}

\section{Model Fit}

To address the ordinal data and the deviations from normal distribution, we used maximum likelihood estimation with robust SEs and a mean- and variance-adjusted test statistic. We compared the three-factor model by Gillath et al. (2009) with a one-factor solution. The onefactor solution was not acceptable $\left(\chi^{2}=199.81, d f=41.81\right.$, $p<.001)$ with CFI (.549), the Tucker-Lewis Index (.498), and the RMSEA (.133 with 95\% CI $=.126, .141)$. For the three-factor model, $\chi^{2}$ was significant $\left(\chi^{2}=111.71, d f=\right.$ $46.19, p<.001)$ indicating an inacceptable fit of the model. Due to the sensitivity to sample size and the assumption of the underlying central $\chi^{2}$ distribution that the model fits the population perfectly, this fit index is known to be somewhat problematic in estimating the goodness of fit (Byrne, 2006). Therefore, the absolute value of the $\chi^{2}$ test is better interpreted as $\chi^{2} / d f$ with values $<5$ are deemed as acceptable (Bollen, 1989). The $\chi^{2} / d f$ ratio is 2.42 which is acceptable. The CFI (.821), the Tucker-Lewis Index (.812), and the RMSEA (RMSEA $=.073$ with $95 \% \mathrm{CI}=.065, .081$ ) were satisfactory. The $\chi^{2}$ difference test with $\Delta \chi^{2}=88.1$ revealed with $d f=4.38, p<.001$, a significant improvement of the one- versus three-factor solution, which is also indicated by better Akaike information criterion (12,898 vs. 12,414$)$ and Bayesian information criterion values $(13,042$ vs. 12,569$)$ of the latter. The overall fit was slightly lower than those found by Gillath et al. (2009; Study 2: CFI $=.90$; RMSEA $=.07$ ) and for the Italian version of the SAAM by Trentini et al. $(2015$; CFI $=.92$; RMSEA $=.056)$. For more information on CFA factor loadings and item parameters, see the table in Electronic Supplementary Material 2.

\section{Descriptive Analyses}

Table 1 provides an overview of the descriptive analyses of the DE-SAAM subscales as well as gender differences. Gender effects for the DE-SAAM score were found for attachment anxiety (Hedges' $g=0.43$ ) and Security $(g=$ 0.39). Women showed significantly higher levels of Anxiety than men $(p=.005)$ as well as higher levels of Security than men $(p=.012)$ and divers $(p=.018)$. No differences between genders were found for Avoidance scores $(g=0.09)$. An effect of relationship status was found for Avoidance $\left(F=11.18, p<.001, \eta^{2}=.09\right)$ and Security $\left(F=34.77, p<.001, \eta^{2}=.23\right)$, but not for Anxiety $(F=$ $\left.0.062, p>.05, \eta^{2}=.01\right)$. Singles scored significantly higher on Avoidance and significantly lower on Security, than individuals in a relationship (Avoidance: $M=2.10, S D=$ $0.62, p=.001$, Security: $M=4.32, \mathrm{~S} D=0.46, p<.001)$ or married participants $(M=1.92 ; S D=0.54, p<.001 ; M=$ 4.33, $S D=0.59, p<.001)$. Higher age predicted less attachment Avoidance $(R=-.18 ; p=.005)$ and higher Security $(R=.13, p=.045)$.

In line with theory, the DE-SAAM subscales Anxiety and Avoidance were uncorrelated $(r=.07, p=.391)$. Security was negatively correlated with Avoidance $(r=-.65, p<.001)$ but not with Anxiety $(r=-.13, p=.076)$. Reported were correlations between latent factors. Observed correlations for Anxiety and Avoidance were $r=.05(p=.467)$. Security was negatively correlated with Avoidance $(r=-.54$,

Table 1. Gender differences and descriptive analyses of the DE-State Adult Attachment Measure (SAAM) subscales

\begin{tabular}{|c|c|c|c|c|c|c|}
\hline \multirow[b]{2}{*}{ Subscale } & \multicolumn{3}{|c|}{$M(S D)$} & \multirow[b]{2}{*}{ Hedges' g } & \multirow[b]{2}{*}{ Skewness } & \multirow[b]{2}{*}{ Kurtosis } \\
\hline & Total & Male & Female & & & \\
\hline Anxiety & $3.21(0.75)$ & $3.03(0.84)$ & $3.35(0.64)$ & 0.43 & -0.26 & -0.10 \\
\hline Avoidance & $2.20(0.68)$ & $2.16(0.72)$ & $2.22(0.64)$ & 0.09 & 0.47 & -0.20 \\
\hline Security & $4.08(0.66)$ & $3.96(0.74)$ & $4.21(0.54)$ & 0.39 & -1.13 & 1.74 \\
\hline
\end{tabular}


$p<.001)$, but not with Anxiety $(r=-.03, p=.586)$. Furthermore, we assessed whether relationship status was related to the SAAM scales. Relationship status was coded as 0 when single and 1 for any other status (married or cohabitating). Relationship status is significantly related with Security $(r=48, p<.001)$ and negatively with Avoidance $(r=-.28, p<.001)$, but not with Anxiety $(r=-.03, p=.674)$.

\section{Reliability}

Internal consistency was assessed with Cronbach's $\alpha$ values and McDonald's omega via the package psych (Revelle, 2019). Reliabilities for Anxiety (.80/.80), Avoidance (.75/ $.76)$, and Security $(.88 / .89)$ were good.

\section{Convergent Validity}

Convergent validity was examined by correlating the DE-SAAM with a frequently used instrument of trait attachment style. Table 2 displays the latent and manifest correlations found between the subscales of the DESAAM and the German version of the ECR (Neumann et al., 2012). As expected, DE-SAAM Anxiety showed positive significant correlations with ECR Anxiety. A negative correlation was found between DE-SAAM Anxiety and ECR Avoidance. DE-SAAM Avoidance was positively correlated with ECR Avoidance and ECR Anxiety. In line with theory, the Security subscale of the DE-SAAM correlated negatively with both ECR Anxiety and ECR Avoidance. Large effects for correlations between corresponding subscales of the DE-SAAM and medium-to-large effects between noncorresponding subscales indicate a satisfying convergent validity of the DE-SAAM subscales.

\section{Discriminant Validity}

To examine discriminant validity correlations of the DESAAM with the German version of the PANAS, a wellvalidated measure for the emotional state was calculated (Table 3). According to theoretical assumptions, DE-SAAM Avoidance was negatively associated with positive affect and positively related to negative affect, while Security was positively related to positive affect and negatively associated with negative affect. Anxiety showed a positive correlation with negative affect and a nonsignificant

Table 2. Latent and observed State Adult Attachment Measure (SAAM) subscale correlations with trait attachment measure (experiences in close relationship [ECR] dimensions)

\begin{tabular}{llll}
\hline & SAAM Anxiety & SAAM Avoidance & SAAM Security \\
\hline ECR Anxiety & $.61^{\star *} / .51^{\star *}$ & $.37^{\star *} / .28^{\star *}$ & $-.45^{\star *} /-.40^{\star *}$ \\
ECR Avoidance & $-.15 /-.15$ & $.79^{\star *} / .34^{\star *}$ & $-.56^{\star *} /-.17$ \\
\hline
\end{tabular}

Note. Latent correlations before the slash/oberserved correlations thereafter. ${ }^{*} p<.01,{ }^{* \star} p<.001$
Table 3. Latent State Adult Attachment Measure (SAAM) scale correlations with nonattachment state measure (Positive and Negative Affect Schedule [PANAS] subscales)

\begin{tabular}{lccc}
\hline & \multicolumn{3}{c}{ SAAM } \\
\cline { 2 - 4 } & Anxiety & Avoidance & Security \\
\hline PANAS negative & $.31^{\star *}$ & $.05^{\star *}$ & $-.50^{\star *}$ \\
PANAS positive & -.01 & $-.26^{*}$ & $.04^{*}$ \\
\hline Note. ${ }^{*} p<.01,{ }^{* *} p<.001$. & &
\end{tabular}

negative correlation with positive affect. Overall, smaller effects regarding correlations with a nonattachment state measure compared to correlations with a trait attachment measure indicate good discriminant validity.

\section{Incremental Validity}

To assess incremental validity, it was tested whether DESAAM scores could predict outcomes of three different well-being and mental health-related measures over and beyond attachment trait measures. For this purpose, a hierarchical regression analysis was used. The results are displayed in Table 4.

Two baseline models (Model 1: DE-SAAM, Model 2: ECR) for each of the dependent variables were calculated to assess the amount of variance accounted for by the DESAAM and the ECR as the only predictor. The DE-SAAM subscales accounted for more variance in each of the dependent variables tested (satisfaction with life: $R^{2}=$ $.308, p<.001$; depressiveness: $R^{2}=.354, p<.001$; anxiety: $R^{2}=.228, p<.001$ ) than the ECR as the predictor (anxiety: $R^{2}=.162, p<.001$; depressiveness: $R^{2}=.254, p<.001$; satisfaction with life: $\left.R^{2}=.186, p<.001\right)$. All DE-SAAM subscales significantly predicted depressiveness and anxiety, but only Security predicted satisfaction with life.

To test the incremental value of the DE-SAAM against age, gender, and the ECR, a hierarchical regression for each of the dependent variables was calculated in Model 3. First, age and gender were entered, followed by the ECR subscales in a second step, and the DE-SAAM subscales in the last step. Adding the DE-SAAM led to a significant increase in the amount of variance explained for all outcome variables (satisfaction with life: $\Delta R^{2}=$ $.170, p<.001$; depressiveness: $\Delta R^{2}=.145, p<.001$; anxiety: $\left.\Delta R^{2}=.119, p<.001\right)$. All DE-SAAM subscales accounted for a small but consistent increase in $R^{2}$ for all dependent variables. When entered simultaneously, DESAAM Security contributed to an increase in $R^{2}$ for anxiety $(b=-0.624)$, depressiveness $(b=-0.544)$, and satisfaction with life $(b=0.673)$. Avoidance accounted for a significant increase in $R^{2}$ for depressiveness $(b=0.197)$. DE-SAAM Anxiety did not predict either of the outcome variables. These results are in line with those found by Gillath et al. (2009, Study 4). 
Table 4. Regression analyses models to assess incremental validity of the DE-State Adult Attachment Measure (SAAM) over experiences in close relationship (ECR) for well-being and mental health outcomes

\begin{tabular}{|c|c|c|c|c|c|c|c|c|c|}
\hline \multirow[b]{2}{*}{ Predictor } & \multicolumn{3}{|c|}{ Satisfaction with life (SWLS) } & \multicolumn{3}{|c|}{ Depressiveness } & \multicolumn{3}{|c|}{ Anxiety } \\
\hline & Model 1 & Model 2 & Model 3 & Model 1 & Model 2 & Model 3 & Model 1 & Model 2 & Model 3 \\
\hline 1. Age & & & .02 & & & -.07 & & & .06 \\
\hline 2. Gender & & & $-.12^{\star}$ & & & .01 & & & 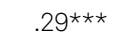 \\
\hline 3. ECR Anxiety & $-.40 * \star \star$ & & $-.21 \star \star$ & $.49 * \star \star$ & & $.30 * \star \star$ & $.38^{\star \star \star}$ & & .14 \\
\hline 4. ECR Avoidance & $-.14^{\star}$ & & -.05 & .11 & & .02 & .10 & & .03 \\
\hline 5. SAAM Anxiety & & -.09 & .04 & & $.15^{\star \star}$ & .00 & & $.22^{\star \star \star}$ & .09 \\
\hline 6. SAAM Avoidance & & -.11 & -.04 & & $.19 * \star$ & $.13^{\star}$ & & $.14^{*}$ & .09 \\
\hline 7. SAAM Security & & $.48^{\star \star \star}$ & $.45^{\star \star \star}$ & & $-.45^{\star \star \star}$ & $-.36^{\star \star \star}$ & & $-.33^{\star \star \star}$ & $-.36^{\star \star \star}$ \\
\hline$\Delta \mathrm{R}^{2}$ & & & $.17 * \star \star$ & & & $.15^{\star \star \star}$ & & & $.12 * \star \star$ \\
\hline Model R2 & $.19 * *$ & $.31 * \star \star$ & $.36 * \star \star$ & $.25^{\star \star \star}$ & $.35^{\star \star \star}$ & $.41^{\star \star \star}$ & $.16^{\star \star \star}$ & $.23^{\star \star \star}$ & $.33^{\star \star \star}$ \\
\hline
\end{tabular}

Note. $N=231$, entries are standardized $\beta$-coefficients of the final model. ${ }^{\star} p<.05,{ }^{\star \star} p<.01,{ }^{\star \star \star} p<.001$.

\section{Study 2}

To test if the German version of the SAAM is sensitive to temporary fluctuations in attachment style, test-retest reliability was examined. Gillath et al. (2009) found reasonable stability over a three-month period (Anxiety = .51 ; Avoidance $=.53$; Security $=.59$ ) in a subsample of 93 participants. The reliability scores were slightly higher than those of other state measures, such as the PANAS, but lower than typical reliability scores for trait measures.

\section{Method}

The software program $G^{*}$ Power was used to calculate the minimum sample size. The goal was to obtain .80 power to detect a medium correlation of .51 (according to those found by Gillath et al., 2009) at the standard .05 alpha error probability, resulting in a minimum required sample size of 23 participants.

Forty-six participants completed the DE-SAAM in an online survey on two survey dates at intervals of 1 week. Furthermore, the survey also included the ECR to test whether the reliability scores of the DE-SAAM differ from those of a trait attachment measure.

\section{Results}

The test-retest reliabilities were $.86, .85$, and .81 for SAAM Avoidance, SAAM Anxiety, and SAAM Security, respectively. For ECR Anxiety, the test-retest correlation was .85, and for ECR Avoidance, it was .73. We further corrected for attenuation to make the test-retest reliabilities comparable. The corrected test-retest correlations were 1.00, .96, and .93 for SAAM Avoidance, SAAM Anxiety, and SAAM Security, respectively. For ECR Anxiety, the test-retest correlation was .98, and for ECR Avoidance, it was 1.00. Given the short time span, all corrected test-retest reliabilities were near upper bound and do not differ.

\section{Study 3}

Study 3 aimed to investigate whether the DE-SAAM can be applied to capture short-time fluctuations in attachment style caused by experimental manipulation. Security priming has shown to be a reliable instrument to induce temporary changes on the attachment dimensions (Gillath \& Karantzas, 2019). We hypothesized that activating attachment security would result in increases in participants' SAAM Security scores and decreases in SAAM Anxiety and Avoidance scores.

\section{Method}

\section{Participants and Procedure}

Participants were asked to complete an online survey on relationships and personality. The survey included questions on sociodemographic data followed by either an attachment security prime or a control task, and the DESAAM to assess state attachment. An automatic algorithm randomly assigned participants either to the security priming group or to the neutral priming group (control). One hundred thirty-nine participants completed the online survey. Thirteen participants had to be excluded due to missing values resulting in a total of 126 participants (72 males, 54 females), with 61 in the security priming condition (34 males, 27 females) and 65 in the neutral priming condition (38 males, 27 females). 


\section{Measures}

To activate the attachment security schema, a supraliminal priming type was used, which has shown to reliably activate security in previous studies (Gillath \& Karantzas, 2019). According to Gillath et al. (2017) (Study 3), participants were asked to write about a moment ("as detailed as possible") in a close personal relationship in which their relationship partner gave them love, comfort, and support. Participants had 5 minutes to complete the task. No word limit was set. In the neutral priming condition (control), participants were asked to recall and write about a time when they engaged in an everyday task with an acquaintance, such as shopping in a store or studying in the library. To assess differences in state attachment between the two priming conditions, the DE-SAAM was used.

\section{Results}

We used a $t$ test to investigate the effect of the priming manipulation on the scores on the DE-SAAM subscales. The results are given in Table 5 .

The results showed that the security prime had an effect on participants' attachment security scores. Participants in the security prime condition scored significantly higher on the SAAM Security subscale than participants in the neutral prime condition $(p=.007, d=0.49)$. Other than hypothesized, no effect of the security prime condition was found for Anxiety and Avoidance with mean differences of $.08(d=0.03)$ and $.21(d=0.10)$, respectively.

Table 5. Results of independent samples $t$ test for priming conditions

\begin{tabular}{lccccc}
\hline & \multicolumn{2}{c}{ Priming conditions } & & & \\
\cline { 2 - 3 } & Security & Neutral & $t$ & $p$ & Cohen's $d$ \\
\hline Anxiety & & & & & \\
$M$ & 4.35 & 4.27 & 0.37 & .714 & 0.03 \\
$S D$ & 1.22 & 1.24 & & & \\
Avoidance & & & & & \\
$M$ & 2.55 & 2.76 & -1.15 & .253 & 0.10 \\
SD & 1.00 & 1.01 & & & \\
Security & & & & & \\
$M$ & 5.99 & 5.45 & 2.75 & .007 & 0.49 \\
SD & 0.95 & 1.23 & & & \\
\hline
\end{tabular}

Note. $N=126$ (with $n=61$ for security prime condition and $n=65$ for neutral prime condition), $d f=124$.

\section{Discussion}

Attachment style was long considered a stable disposition based on early childhood experiences with caregivers. Within the last two decades, research on priming attachment security has led to new insights considering attachment style stability (Fraley \& Roisman, 2019). Several studies demonstrated that priming attachment security (e.g., by imagining relationship situations associated with feeling secure) could temporarily increase attachment security levels by activating specific working models (Carnelley \& Rowe, 2007, 2010; Gillath \& Karantzas, 2019; Gillath et al., 2008). Although there seems to be an enduring attachment style (working model), temporary fluctuations of Security (and Anxiety and Avoidance) levels can occur due to contextual or situational changes.

Frequently used instruments, such as the ECR (Brennan et al., 1998), are designed to capture stable and enduring attachment style levels by explicitly asking for general experiences in relationships. Gillath et al. (2009) developed the SAAM, a self-report measure to assess temporary variations in the underlying attachment dimensions Anxiety, Avoidance, and Security. As there are important correlates of attachment style, such as outcomes of relationship quality, well-being, and mental health, further investigations of contextual and situational influences on attachment dimensions are of great interest in all cultures. To allow research on state adult attachment with Germanspeaking samples, we tested the psychometric properties of a German version of the SAAM (DE-SAAM) as well as its fit with the proposed three-factor structure.

Gender effects were found in line with previous findings with women scoring higher on Anxiety and Security (Bartholomew \& Horowitz, 1991). Furthermore, a negative correlation of avoidant attachment with age was found, consistent with results reported in previous studies (Chopik et al., 2013).

The hypothesized three-factor model of the SAAM (Avoidance, Anxiety, and Security) was supported for the DE-SAAM. Model fit indices were satisfying although fit indices indicated a poorer fit than that of the original SAAM (Gillath et al., 2009). Apart from a moderate negative correlation of avoidance and security, the latent variables were uncorrelated according to the underlying theory. This pattern also emerged for the original SAAM (Gillath et al., 2009). DE-SAAM subscales showed high internal consistency.

Furthermore, convergent, discriminant, and incremental validity were examined. As expected, the DE-SAAM subscales showed strong correlations with the corresponding subscales of an attachment trait measure (Gillath et al., 2009). Although correlations with subscales of the 
German version of the PANAS (Breyer \& Bluemke, 2016) were lower, they still showed the expected patterns, supporting the state interpretation of the test scores. Incremental validity was tested using hierarchical regression. The results showed that DE-SAAM subscale scores predict outcomes of mental health (depressiveness and anxiety) and well-being (satisfaction with life) over and beyond trait attachment as assessed by the ECR. Most notably, the subscale Security contributed significantly to the prediction of all three outcomes beyond the ECR dimensions anxiety and avoidance. This supports the concept of Security as an independent attachment dimension as suggested by Gillath et al. (2009). However, it remains unclear whether DE-SAAM Security scores capture state attachment security or an independent dimension of trait attachment security that the ECR does not cover. Furthermore, the results raise the question whether the DESAAM Anxiety and Avoidance subscales capture state attachment.

Retest reliabilities of the SAAM subscales did not differ from those of the ECR over a period of one week. This relatively short interval makes the systematic occurrence of situational or contextual changes that influence attachment style (e.g., relationship dissolution or finding a new partner) in a small sample unlikely (Cozzarelli et al., 2003). Moreover, items of the SAAM and the ECR are relatively similar and were both presented in the survey. This might have led to response bias (e.g., confirmation and memory effects).

Priming attachment security by asking participants to recall and write about a situation in a close relationship in which they received love and support was associated with higher scores on the DE-SAAM Security subscale compared to the control group. Thus, the DE-SAAM can capture short-time fluctuations in attachment security caused by laboratory manipulation. Other than expected, no effect of the security prime condition was found for Avoidance and Anxiety. Only a slight decrease in means could be observed for Avoidance. First of all, the three-factor model of the SAAM conceptualizes Security as a distinct dimension. Thus, it is plausible that a security prime particularly affects this dimension. Furthermore, participants were asked to recall a situation in which they received love, comfort, and support from a relationship partner. This is somewhat typical for the Security dimension (e.g., "I feel like I have someone to rely on" and "If something went wrong right now I feel like I could depend on someone"). Moreover, recalling a situation in which one received love and support might activate the Anxiety schema, for example, in individuals who are (temporarily) separated from their relationship partner. Those might suddenly long for this kind of love and support (e.g., "I wish someone close could see me now"). As mentioned above, the sample consisted of military students to a high amount, who typically live on campus away from friends, families, and partners. Thus, future research should investigate the effects of more general security primes as well as insecurity primes on the scores of the DE-SAAM dimensions (Cafferty et al., 1994).

Most notably, the limitations of this study resulted from the limited sample size as structural equation modeling is considered a large sample method. With a total of 231 participants, the sample size was just meeting the required minimum according to the "10-times rule" (Hair et al., 2011) with 21 manifest variables (required sample size of 210). This rule is a fairly liberal estimator for minimum required sample sizes using structural equations, which may also lead to inaccurate estimates (Goodhue et al., 2012). The number of participants in this study still lies between those found in previous research on the SAAM and its translated versions. Sample sizes ranged from 180 for the Korean translation (K-SAAM; Park \& Lee, 2012), 400 for the Italian version (IT-SAAM; Trentini et al., 2015), 1,433 for the original SAAM (study 4; Gillath et al., 2009), and 2,290 for the Chinese version (Ma et al., 2012). Moreover, the samples consist of military university students to a large extent. Individuals with lower scores on the Big Five Scale Neuroticism are more likely to enter the military (Jackson et al., 2012). Furthermore, low levels of Neuroticism are associated with less attachment anxiety and avoidance, which are also forms of insecurity (Noftle \& Shaver, 2006). Thus, military students might be less prone to insecurity caused by contextual changes. For a better estimation of model fit parameters, further research using large and more diverse samples regarding the occupation would be beneficial.

In summary, the psychometric properties of the DESAAM provide some evidence supporting the interpretation of the test scores as state attachment. However, the evidence is strongest for the Security subscale while it remains unclear to which extent DE-SAAM Avoidance and Anxiety scores capture the state aspect of attachment. As attachment style is associated with different outcomes of mental health and well-being, it is critical to understand mechanisms that affect and shape attachment style. Studies showing that repeated security priming can lead to lasting effects on attachment security levels (Carnelley \& Rowe, 2007; Gillath et al., 2008; Gillath \& Karantzas, 2019) hint at the potential of systematic enhancement of attachment security to improve mental health and well-being (e.g., attachment-based therapy; Diamond et al., 2016). The application of a SAAM in the German language area could be of great use to identify 
critical events and contexts related to fluctuations in attachment dimensions and to monitor the development of (temporary) changes. Thus, further research is needed to ensure the sensitivity of the DE-SAAM subscales Anxiety and Avoidance to temporary changes in attachment style. Furthermore, to test applicability on the individual level, future research should focus on the psychometric properties of the DE-SAAM in intraindividual contexts.

\section{Electronic Supplementary Material}

The electronic supplementary material is available with the online version of the article at https://doi.org/ 10.1027/2698-1866/a000006

ESM 1. DE-SAAM

ESM 2. Table with CFA factor loadings and item parameters

\section{References}

Ainsworth, M. D. S. (1978). Patterns of attachment: A psychological study of the strange situation. Erlbaum.

Baldwin, M. W., \& Fehr, B. (1995). On the instability of attachment style ratings. Personal Relationships, 2(3), 247-261. https://doi. org/10.1111/j.1475-6811.1995.tb00090.x

Baldwin, M. W., Keelan, J. P. R., Fehr, B., Enns, V., \& Koh-Rangarajoo, E. (1996). Social-cognitive conceptualization of attachment working models: Availability and accessibility effects. Journal of Personality and Social Psychology, 71(1), 94-109. https://doi.org/10.1037/0022-3514.71.1.94

Bartholomew, K. (1990). Avoidance of intimacy: An attachment perspective. Journal of Social and Personal Relationships, 7(2), 147-178. https://doi.org/10.1177/0265407590072001

Bartholomew, K., \& Horowitz, L. M. (1991). Attachment styles among young adults: A test of a four-category model. Journal of Personality and Social Psychology, 61(2), 226-244. https://doi.org/ 10.1037/0022-3514.61.2.226

Bifulco, A., Moran, P. M., Ball, C., \& Bernazzani, O. (2002). Adult attachment style. I: Its relationship to clinical depression. Social Psychiatry and Psychiatric Epidemiology, 37(2), 50-59. https:// doi.org/10.1007/s127-002-8215-0

Bollen, K. A. (1989). Introduction. In K. A. Bollen (Ed.), Structural equations with latent variables (pp. 1-9). https://doi.org/10. 1002/9781118619179.ch1

Bosmans, G., Bowles, D. P., Dewitte, M., De Winter, S., \& Braet, C. (2014). An experimental evaluation of the State Adult Attachment Measure: The Influence of attachment primes on the content of state attachment representations. Journal of Experimental Psychopathology, 5(2), 134-150. https://doi.org/10. 5127/jep.033612

Bowlby, J. (1969). Attachment and loss, Vol. 1: Attachment. Basic Books.

Bowlby, J. (1982). Attachment and loss: Retrospect and prospect. American Journal of Orthopsychiatry, 52(4), 664-678. https:// doi.org/10.1111/j.1939-0025.1982.tb01456.x
Brennan, K. A., Clark, C. L., \& Shaver, P. R. (1998). Self-report measurement of adult attachment: An integrative overview. In J. A. Simpson \& W. S. Rholes (Eds.), Attachment theory and close relationships (pp. 46-76). Guilford

Breyer, B., \& Bluemke, M. (2016). Deutsche version der positive and negative affect schedule PANAS (GESIS Panel) [German version of the positive and negative affect schedule PANAS (GESIS Panel)]. https://doi.org/https://doi.org/10.6102/zis242

Byrne, B. M. (2006). Structural equation modeling with EQS: Basic concepts, applications, and programming (2nd ed.). Routledge. https://doi.org/10.4324/9780203726532

Cafferty, T. P., Davis, K. E., Medway, F. J., O'Hearn, R. E., \& Chappell, K. D. (1994). Reunion dynamics among couples separated during operation desert storm: An attachment theory analysis. In K. Bartholomew \& D. Perlman (Eds.), Attachment processes in adulthood. Advances in personal relationships (pp. 309-330). Jessica Kingsley Publishers.

Carnelley, K. B., \& Rowe, A. C. (2007). Repeated priming of attachment security influences later views of self and relationships. Personal Relationships, 14(2), 307-320. https://doi.org/10.1111/j.1475-6811. 2007.00156.x

Carnelley, K. B., \& Rowe, A. C. (2010). Priming a sense of security: What goes through people's minds? Journal of Social and Personal Relationships, 27(2), 253-261. https://doi.org/10.1177/ 0265407509360901

Chopik, W. J., Edelstein, R. S., \& Fraley, R. C. (2013). From the cradle to the grave: Age differences in attachment from early adulthood to old age. Journal of Personality, 81(2), 171-183. https:// doi.org/10.1111/j.1467-6494.2012.00793.x

Cozzarelli, C., Karafa, J. A., Collins, N. L., \& Tagler, M. J. (2003). Stability and change in adult attachment styles: Associations with personal vulnerabilities, life events, and global construals of self and others. Journal of Social and Clinical Psychology, 22(3), 315-346. https://doi.org/10.1521/jscp.22.3.315.22888

Diamond, G., Russon, J., \& Levy, S. (2016). Attachment-based family therapy: A review of the empirical support. Family Process, 55(3), 595-610. https://doi.org/10.1111/famp.12241

Diener, E., Emmons, R. A., Larsen, R. J., \& Griffin, S. (1985). The satisfaction with life scale. Journal of Personality Assessment, 49(1), 71-75. https://doi.org/10.1207/s15327752jpa4901_13

Feeney, J. A., \& Noller, P. (1992). Attachment style and romantic love: Relationship dissolution. Australian Journal of Psychology, 44(2), 69-74. https://doi.org/10.1080/00049539208260145

Feeney, J. A., Noller, P., \& Hanrahan, M. (1994). Attachment Style Questionnaire (ASQ) [Database record]. APA PsycTests. https:// doi.org/10.1037/t29439-000

Fraley, R. C., \& Roisman, G. I. (2019). The development of adult attachment styles: Four lessons. Current Opinion in Psychology, 25, 26-30. https://doi.org/10.1016/j.copsyc.2018.02.008

Fraley, R. C., Waller, N. G., \& Brennan, K. A. (2000). An item response theory analysis of self-report measures of adult attachment. Journal of Personality and Social Psychology, 78(2), 350-365. https://doi.org/10.1037/0022-3514.78.2.350

Gillath, O., Hart, J., Noftle, E. E., \& Stockdale, G. D. (2009). Development and validation of a State Adult Attachment Measure (SAAM). Journal of Research in Personality, 43(3), 362-373. https://doi.org/10.1016/j.jrp.2008.12.009

Gillath, O., \& Karantzas, G. (2019). Attachment security priming: A systematic review. Current Opinion in Psychology, 25, 86-95. https://doi.org/10.1016/j.copsyc.2018.03.001

Gillath, O., Karantzas, G. C., \& Selcuk, E. (2017). A net of friends: Investigating friendship by integrating attachment theory and social network analysis. Personality and Social Psychology Bulletin, 43(11), 1546-1565. https://doi.org/10.1177/0146167217719731

Gillath, O., Selcuk, E., \& Shaver, P. R. (2008). Moving toward a secure attachment style: Can repeated security priming help? 
Social and Personality Psychology Compass, 2(4), 1651-1666. https://doi.org/10.1111/j.1751-9004.2008.00120.x

Goodhue, D. L., Lewis, W., \& Thompson, R. (2012). Does PLS have advantages for small sample size or non-normal data? MIS Quarterly, 36(3), 981. https://doi.org/10.2307/41703490

Griffin, D. W., \& Bartholomew, K. (1994). Models of the self and other: Fundamental dimensions underlying measures of adult attachment. Journal of Personality and Social Psychology, 67(3), 430-445. https://doi.org/10.1037/0022-3514.67.3.430

Hair, J. F., Ringle, C. M., \& Sarstedt, M. (2011). PLS-SEM: Indeed a silver bullet. Journal of Marketing Theory and Practice, 19(2), 139-152. https://doi.org/10.2753/MTP1069-6679190202

Hammond, J. R., \& Fletcher, G. J. O. (1991). Attachment styles and relationship satisfaction in the development of close relationships. New Zealand Journal of Psychology, 20(2), 56-62.

Hazan, C., \& Shaver, P. (1987). Romantic love conceptualized as an attachment process. Journal of Personality and Social Psychology, 52(3), 511-524. https://doi.org/10.1037/0022-3514.52.3.511

Jackson, J. J., Thoemmes, F., Jonkmann, K., Lüdtke, O., \& Trautwein, U. (2012). Military training and personality trait development: Does the military make the man, or does the man make the military? Psychological Science, 23(3), 270-277. https://doi. org/10.1177/0956797611423545

Janke, S., \& Glöckner-Rist, A. (2012). Deutsche Version der Satisfaction with Life Scale (SWLS) [German version of the Satisfaction with Life Scale]. Zusammenstellung sozialwissenschaftlicher Items und Skalen (ZIS). https://doi.org/10.6102/zis147

Jones, J. D., Fraley, R. C., Ehrlich, K. B., Stern, J. A., Lejuez, C. W., Shaver, P. R., \& Cassidy, J. (2018). Stability of attachment style in adolescence: An empirical test of alternative developmental processes. Child Development, 89(3), 871-880. https://doi.org/10.1111/cdev.12775

Karreman, A., \& Vingerhoets, A. J. J. M. (2012). Attachment and well-being: The mediating role of emotion regulation and resilience. Personality and Individual Differences, 53(7), 821-826. https://doi.org/10.1016/j.paid.2012.06.014

Kirkpatrick, L. A., \& Hazan, C. (1994). Attachment styles and close relationships: A four-year prospective study. Personal Relationships, 1(2), 123-142. https://doi.org/10.1111/j.1475-6811.1994.tb00058.x

Ma, S.-C., Li, P., Zhang, H., Zhao, M.-R., Li, X.-T., Tian, Z.-X., \& Omri, G. (2012). The Chinese version of state adult attachment measure (SAAM): It's applicability in Chinese college students. Chinese Journal of Clinical Psychology, 20(1), 5-10.

Mohr, G., \& Müller, A. (2014a). Angst im nichtklinischen Kontext [Anxiety in a nonclinical context]. Zusammenstellung sozialwissenschaftlicher Items und Skalen (ZIS). https://doi.org/10. $6102 /$ zis 80

Mohr, G., \& Müller, A. (2014b). Depressivität im nichtklinischen Kontext [Depressiveness in nonclinical contexts]. Zusammenstellung sozialwissenschaftlicher Items und Skalen (ZIS). https:// doi.org/https://doi.org/10.6102/zis79

Neumann, E., Rohmann, E., \& Bierhoff, H.-W. (2012). BoBi - Bochumer Bindungsfragebogen. ZPID (Leibniz Institute for Psychology Information) - Testarchiv. https://doi.org/10.23668/ PSYCHARCHIVES.377

Noftle, E. E., \& Shaver, P. R. (2006). Attachment dimensions and the big five personality traits: Associations and comparative ability to predict relationship quality. Journal of Research in Personality, 40(2), 179-208. https://doi.org/10.1016/j.jrp.2004.11.003

Park, S. D., \& Lee, W. K. (2012). The reliability and validity of the Korean version of State Adult Attachment Measure. Journal of Korean Neuropsychiatric Association, 51(4), 147. https://doi.org/ 10.4306/jknpa.2012.51.4.147
Revelle, W. (2019). psych: Procedures for personality and psychological research. https://CRAN.R-project.org/package=psych

Roberts, J. E., Gotlib, I. H., \& Kassel, J. D. (1996). Adult attachment security and symptoms of depression: The mediating roles of dysfunctional attitudes and low self-esteem. Journal of Personality and Social Psychology, 70(2), 310-320. https://doi.org/ 10.1037/0022-3514.70.2.310

Rothbart, M. K., Ahadi, S. A., \& Evans, D. E. (2000). Temperament and personality: Origins and outcomes. Journal of Personality and Social Psychology, 78(1), 122-135. https://doi.org/10.1037// 0022-3514.78.1.122

Rowe, A., \& Carnelley, K. B. (2003). Attachment style differences in the processing of attachment-relevant information: Primed-style effects on recall, interpersonal expectations, and affect. Personal Relationships, 10(1), 59-75. https://doi.org/10.1111/1475-6811.00036

Shaver, P. R., \& Brennan, K. A. (1992). Attachment styles and the "Big Five" personality traits: Their connections with each other and with romantic relationship outcomes. Personality and Social Psychology Bulletin, 18(5), 536-545. https://doi.org/10.1177/0146167292185003

Sibley, C. G., Fischer, R., \& Liu, J. H. (2005). Reliability and validity of the revised experiences in close relationships (ECR-R) selfreport measure of adult romantic attachment. Personality and Social Psychology Bulletin, 31(11), 1524-1536. https://doi.org/ 10.1177/0146167205276865

Stöven, L. M., \& Herzberg, P. Y. (2020). SAAM German version [Data set]. https://osf.io/xsqju/?view_only=6c7b4541e2d04ff193bd8636d38306f1

Trentini, C., Foschi, R., Lauriola, M., \& Tambelli, R. (2015). The state adult attachment measure (SAAM): A construct and incremental validity study. Personality and Individual Differences, 85, 251-257. https://doi.org/10.1016/j.paid.2015.05.016

Watson, D., Clark, L. A., \& Tellegen, A. (1988). Development and validation of brief measures of positive and negative affect: The PANAS scales. Journal of Personality and Social Psychology, 54(6), 1063-1070. https://doi.org/10.1037/0022-3514.54.6.1063

\section{History}

Received June 17, 2020

Revision received December 1, 2020

Accepted December 9, 2020

Published online February 12, 2021

Section: Differential Psychology

\section{Conflict of Interest}

The authors have no known conflict of interest to disclose.

\section{Open Data}

The research data are archived and can be accessed under the Open Science Framework link https://osf.io/xsqju/.

\section{ORCID}

Lynne Marie Stöven

(iD) https://orcid.org/0000-0002-8920-2674

Philipp Yorck Herzberg

(D) https://orcid.org/0000-0003-1662-7564

\section{Lynne M. Stöven}

Department of Psychology Helmut Schmidt University Holstenhofweg 85 22043 Hamburg Germany lynne.stoeven@hsu-hh.de 